\title{
The effects of experience on performance in Wason's selection task
}

\author{
JAMES R. COX and RICHARD A. GRIGGS \\ University of Florida, Gainesville, Florida 32611
}

\begin{abstract}
The Wason selection task is a hypothetico-deductive reasoning problem employing the logical rule of implication. Recent studies have indicated that performance on this task may be related to subjects' experience with the task content. Five versions of the task that differed in the manner in which they were related to the subjects' experience with a familiar implication relationship were examined. The correct solution rate varied as a function of both the subjects' extraexperimental and intraexperimental experience. A memory-cuing/reasoning-by-analogy explanation is proposed to account for the direct relationship between performance and the degree of similarity to subjects' experience.
\end{abstract}

This study is concerned with the effects of prior experience on performance in Wason's four-card selection task (Wason, 1966, 1968). In its basic form, the selection task requires reasoning about an implication rule of the form "If $p$ then $q$," where $p$ and $q$ are abstract terms (usually letters and numbers) having no previously specified relationship experienced by the subjects. For example, the subject might be presented with the rule, "If there is an A on one side of the card, then there is a 4 on the other side" and four cards showing A, D, 4, and 7 ( $p$, not $p, q$, and not $q$, respectively). The subject is told that each card has a letter on one side and a number on the other side and is asked to select just those cards that need to be turned over in order to determine whether the rule is true or false.

The correct answer is $\mathrm{p}$ and not $\mathrm{q}$ ( $\mathrm{A}$ and 7 in the example), since only the combination of $p$ and not $q$ can falsify an implication rule. An odd number might be on the other side of the A card, and a vowel might be on the reverse side of the 7 card. The correct response rate on the basic form of this task is ordinarily less than $10 \%$ (see Wason \& Johnson-Laird, 1972, for a review of the early literature on this task and Evans, 1982 and Griggs, in press, for recent reviews). The two most common errors are failing to select the not-q card (7 in the example) and unnecessarily including the $\mathrm{q}$ card (4 in the example).

The task has been modified by several experimenters to investigate the effects of stating the implication rule in terms of more realistic content. Johnson-Laird, Legrenzi, and Sonino-Legrenzi (1972), Van Duyne (1974), and Wason and Shapiro (1971, Experiment 2) found dramatically improved performance on the task (greater than $50 \%$ correct) using thematic materials; for example, in the Wason and Shapiro study, rules

Requests for reprints should be sent to Richard A. Griggs, Department of Psychology, University of Florida, Gainesville, Florida 32611. about journeys to cities by different modes of transportation were used. ${ }^{1}$ Such improvement in correct responding for thematic content is referred to as the thematic-materials effect.

Recently, however, the robustness of the thematicmaterials effect has been seriously questioned. Manktelow and Evans (1979) did not observe the effect when the materials were cards describing foods and drinks and the rules involved the relationship of their consumption; for example, "If I eat beef, then I drink gin." Reich and Ruth (in press) and Yachanin and Tweney (1982) have replicated Manktelow and Evans's failure to find facilitation for food-and-drink rules. Manktelow and Evans (Experiment 5) also failed to find an effect in an almost exact replication of the Wason and Shapiro (1971) study. Brown, Keats, Keats, and Seggie (1980), Griggs and Cox (in press), and Yachanin and Tweney (1982) have also recently failed to find a thematicmaterials effect for the type of thematic content used by Wason and Shapiro (however, see Pollard, 1981). Given these recent findings, the facilitation of the locations and modes-of-transportation thematic content hardly seems reliable. Recent studies have also failed to replicate Van Duyne's (1974) results for rules about students' schools and major fields of study (Yachanin \& Tweney, 1982) and Johnson-Laird et al.'s (1972) findings for postal rules (Griggs \& Cox, in press).

However, Griggs and Cox (in press) did observe the thematic-materials effect ( $74 \%$ correct responding) for an implication rule that involved the legal drinking age in Florida: "If a person is drinking beer, then the person must be over 19." The subjects were instructed to imagine that they were police officers responsible for ensuring the regulation was followed. They were presented with four cards, labeled "DRINKING BEER," "DRINKING COKE," "16 YEARS OF AGE," and "22 YEARS OF AGE," that represented four people sitting at a table. The task was to select those people (cards) for which further information needed to be 
obtained to determine whether or not the rule was being violated.

Based on an earlier proposal of Manktelow and Evans (1979), Griggs and Cox (in press) presented arguments in favor of a memory-cuing hypothesis to explain the contradictory findings concerning the thematicmaterials effect. This memory-cuing hypothesis proposed that performance on the selection task is significantly facilitated only when presentation of the task allows the subject to recall past experience with the content of the problem, the relationship expressed, and a counterexample to the rule governing the relationship.

Questionnaire data obtained by Griggs and Cox (in press) demonstrated that the undergraduate student population from which their experimental subjects had been drawn had experience with the content of, the relationship for, and counterexamples to the drinkingage implication rule. This was not true of the subjects in their replication of the Johnson-Laird et al. (1972) postal rule study. The American subjects did not have experience with a relationship between sealed and unsealed envelopes with varying amounts of postage, as did the University of London subjects in the JohnsonLaird et al. study. Around the time of the JohnsonLaird et al. study, there had been a postal regulation in England requiring more postage for sealed letters. Thus, the differences in the American and British subjects' past experiences could explain the differences in performance for this particular type of thematic content.

According to the memory-cuing hypothesis, when subjects are given the selection task, they search memory for experiences cued by the problem content. When the implication rule is related to specific past experience, each card is analyzed in terms of the possibility of getting information from it based on the relevant past experience, rather than the card's logical status. For example, in the Griggs and Cox (in press) drinking-age problem (DAP), subjects tend not to select the card "22 YEARS OF AGE" because they know that people this age can drink what they want. On the other hand, if no experiences are applicable, as in the basic abstract version of the task, subjects tend to engage in cognitive short-circuiting responses such as matching-choosing the cards mentioned in the problem, that is, $p$ and $q$ (see Evans, 1982, in press, for detailed descriptions of the research on the abstract task and matching bias).

Intermediate to the extremes of specific applicable experience and no related experience are cases in which the subjects have had experiences that are analogous in some respects. In these cases, general experience with analogous situations are used to generate the responses.

There is evidence for this memory-cuing/reasoningby-analogy process in the Johnson-Laird et al. (1972) study. In one condition, British subjects were required to reason about Italian stamps of various values for the implication rule: "If a letter is sealed, then it has a 50 lire stamp on it." If subjects recognized this rule as analogous to the English postal regulation requiring more postage on a sealed envelope, then it is likely that they could have used their past experience to respond to the task. In fact, Johnson-Laird et al. found no difference between the Italian and British stamp conditions.

The suggestion that subjects do transfer problem solving strategies from experience of specific situations to others with analogous features has also been supported by a recent finding of Golding (Note 1). Her findings also strongly support the memory-cuing hypothesis as an explanation for the difference between the postal rule results of Johnson-Laird et al. (1972) and those of Griggs and Cox (in press). Golding gave an abstract task and an updated, realistic version of the stamp-and-envelope task to British subjects ranging in age from 20 to 70 years. She found no difference in performance between subjects under 45 and those over 45 on the abstract version of the task; however, she did find a significant difference between age groups on the realistic version. The younger group was correct $9 \%$ $(2 / 22)$ of the time, whereas the older group was correct $59 \%(13 / 22)$ of the time. Golding argued that the over45 group was able to perform significantly better because of their past experience with the old postal system that required more postage for a sealed envelope. These subjects profitted from general experience. They responded to the updated task in a manner that would match their responses to the analogous content of their specific experience with the old stamp system and postal regulation.

Another source of evidence that suggests that memory cuing of general experience can facilitate performance on the four-card selection task has been provided by Roy D'Andrade (described in Rumelhart, 1980, Note 2). D'Andrade has devised a version of the task in which subjects are instructed to imagine they are managers in a Sears store and are responsible for checking receipts to determine whether the rule "If a purchase exceeds $\$ 30$, then the receipt must be approved by the department manager" was followed. The selection cards are four receipts: for $\$ 45$, for $\$ 15$, signed, and unsigned. Correct performance on this task (nearly $70 \%$ ) was significantly greater than performance on the abstract version of the task. Mandler (Note 3) reports informally replicating this result several times with college students. Although it is unlikely the subjects have had specific experience as store managers, they have certainly had experience with analogous materials and relationships such as "If a credit card slip is properly filled out, then sign it" or "If the check is made out correctly, then endorse the back." Thus, the results for D'Andrade's problem are clearly consistent with a memory-cuing/ reasoning-by-analogy process.

In the following set of experiments, further evidence is presented in support of the memory-cuing/reasoningby-analogy hypothesis, and evidence is presented that 
suggests subjects' immediate experiences with the content and relationships presented on the selection task can affect their performance on subsequent analogous problems. In each of the experiments, the possibility that transfer exists between problems is considered.

\section{EXPERIMENT 1}

There are two robust findings in the selection task studies concerned with the thematic-materials effect. First, there is the ubiquitous poor performance on problems that use abstract content; second, there is the related finding that even when good performance is obtained with thematic materials, there is no positive transfer from a thematic problem to an abstract problem (e.g., Griggs \& Cox, in press; Johnson-Laird et al., 1972).

Positive transfer among problems would be a possibility if the problems were related in a way that allowed the subjects to recall a solution in one domain and reason by analogy to the solution in another domain. For example, if a subject solved the DAP by recalling that a person drinking beer and being under 19 violated the rule "If drinking beer, then over 19," then they could solve the problem "If a vowel, then an even number" by reasoning that for this problem "a vowel" is equivalent to "drinking beer" and "an even number" is equivalent to "over 19." However, the terms of the two problems share no analogous properties, so it is highly unlikely that the reasoning-by-analogy strategy would be generated. The possibility for analogical reasoning would be much greater, though, if the problems had terms that shared many properties with applic. able experiences; for instance, reasoning about 40- and 50 -lire postage when subjects have had experience with 4- and 5-pence postage, as in Johnson-Laird et al. (1972).

Experiment 1 investigated the possibility of transfer by presenting problems that vary in the degree to which their terms can be considered analogous with a problem that is likely to be solved by memory cuing. Three versions of the selection task were used: (1) the DAP of Griggs and Cox (in press), (2) the standard abstract version, and (3) a new version involving the color of people's apparel and their age. The last problem was identical to the DAP except that it involved two colors of apparel (blue and green) rather than drinking beer or Coke.

The content of the abstract version of the task is not very familiar to most subjects. A situation like that described in the abstract version could only imaginably be expected to occur in some formal presentation in a logic, computer programming, or mathematics course. However, the apparel-color problem (ACP) is analogous in some respects to the subjects' experience. Subjects have, for example, been in many natural situations in which the joint occurrence of their age and some other factor must be considered. The legal age for drinking, driving, and voting are a few examples. In other respects, this problem is not directly related to the subjects' experience, since in all likelihood they would have never been in a situation constraining the relationship of apparel color and age. Thus, these two versions of the task allow an examination of the memory-cuing/ reasoning-by-analogy hypothesis. According to this hypothesis, facilitation should be observed for the ACP, especially when it follows the DAP. No facilitation would be predicted for the abstract version.

\section{Method}

Subjects. One hundred and forty-four undergraduates at the University of Florida participated as part of course requirements for an introductory class in psychology.

Design. Subjects were assigned to one of six groups created by the permutations of three forms of the selection task. The six groups were created so that all possible presentation orders of the three problem types could be examined. The random assignment of subjects to groups was done by the order in which subjects signed up to participate.

Materials and Procedure. The three problems were presented in a booklet with one problem per page to subjects in groups ranging in size from 8 to 22 . Subjects were instructed to reason carefully before responding, to complete each problem before going to the next, and in no case to go back to a problem that they previously had seen.

Four rectangular boxes labeled A, B, 2, and 3 were at the top of the page for the standard selection task (abstract problem, AP). Below these boxes were the following instructions:

"The cards above have information on both sides. On one side of a card is a letter, and on the other side is a number. "Here is a rule: IF A CARD HAS AN A ON ONE SIDE, THEN IT HAS A 3 ON THE OTHER SIDE.

"Select those cards that you definitely need to turn over to determine whether or not the cards are violating the rule."

The DAP had exactly the same format, but the text was as follows.

"On this task imagine you are a police officer on duty. It is your job to ensure that people conform to certain rules. The cards above have information about four people sitting at a table. On one side of a card is a person's age and on the other side of the card is what a person is drinking. Here is a rule: IF $A$ PERSON IS DRINKING BEER, THEN THE PERSON MUST BE OVER 19. Select those cards that you definitely need to turn over to determine whether or not the people are violating the rule."

The four boxes at the top of the page representing the four cards were labeled "DRINKING A BEER," "DRINKING A COKE," "16 YEARS OF AGE," and " 22 YEARS OF AGE."

The ACP also used this format, but the rule was "If a person is wearing blue, then the person must be over 19," and the four boxes contained "WEARING BLUE," "WEARING GREEN," "16 YEARS OF AGE," and " 22 YEARS OF AGE." On one side of each card was a person's age, and on the other side was the color the person was wearing.

\section{Results and Discussion}

The frequencies of selections for each problem as a function of presentation position are given in Table 1 . There are 16 possible answers to the selection task; the 5 most frequently occurring selections are provided in Table 1. Four of the five responses occurred more frequently than expected by chance $(27$ times). The 
Table 1

Selection Frequencies as a Function of Problem and Presentation Position in Experiment 1

\begin{tabular}{|c|c|c|c|c|c|c|}
\hline \multirow[b]{2}{*}{$\begin{array}{l}\text { Presentation } \\
\text { Position }\end{array}$} & \multicolumn{6}{|c|}{ Selection Frequency } \\
\hline & $\mathrm{p}, \overline{\mathrm{q}}$ & $\mathrm{p}$ & $\mathrm{p}, \mathrm{q}$ & $\overline{\mathrm{p}}, \overline{\mathrm{q}}$ & $\begin{array}{l}\mathrm{p}, \overline{\mathrm{p}}, \\
\mathrm{q}, \overline{\mathrm{q}}\end{array}$ & Other \\
\hline \multicolumn{7}{|c|}{ Drinking-Age Problem (DAP) } \\
\hline $\begin{array}{l}\text { DAP, ACP, AP } \\
\text { DAP, AP, ACP } \\
\text { ACP, DAP, AP } \\
\text { AP, DAP, ACP } \\
\text { ACP, AP, DAP } \\
\text { AP, ACP, DAP }\end{array}$ & $\begin{array}{l}17 \\
19 \\
12 \\
13 \\
14 \\
12\end{array}$ & $\begin{array}{l}2 \\
3 \\
4 \\
4 \\
2 \\
4\end{array}$ & $\begin{array}{l}0 \\
0 \\
0 \\
1 \\
1 \\
3\end{array}$ & $\begin{array}{l}0 \\
0 \\
0 \\
3 \\
0 \\
0\end{array}$ & $\begin{array}{l}0 \\
0 \\
0 \\
0 \\
1 \\
2\end{array}$ & $\begin{array}{l}5 \\
2 \\
8 \\
3 \\
6 \\
3\end{array}$ \\
\hline \multicolumn{7}{|c|}{ Apparel-Color Problem (ACP) } \\
\hline $\begin{array}{l}\text { ACP, DAP, AP } \\
\text { ACP, AP, DAP } \\
\text { DAP, ACP, AP } \\
\text { AP, ACP, DAP } \\
\text { DAP, AP, ACP } \\
\text { AP, DAP, ACP }\end{array}$ & $\begin{array}{r}5 \\
7 \\
18 \\
4 \\
13 \\
15\end{array}$ & $\begin{array}{l}6 \\
4 \\
3 \\
5 \\
2 \\
3\end{array}$ & $\begin{array}{l}2 \\
4 \\
0 \\
6 \\
2 \\
1\end{array}$ & $\begin{array}{l}2 \\
4 \\
1 \\
2 \\
1 \\
2\end{array}$ & $\begin{array}{l}1 \\
1 \\
0 \\
4 \\
0 \\
0\end{array}$ & $\begin{array}{l}8 \\
4 \\
2 \\
3 \\
6 \\
3\end{array}$ \\
\hline \multicolumn{7}{|c|}{ Abstract Problem (AP) } \\
\hline $\begin{array}{l}\text { AP, DAP, ACP } \\
\text { AP, ACP, DAP } \\
\text { DAP, AP, ACP } \\
\text { ACP, AP, DAP } \\
\text { DAP, ACP, AP } \\
\text { ACP, DAP, AP }\end{array}$ & $\begin{array}{l}2 \\
0 \\
1 \\
1 \\
1 \\
0\end{array}$ & $\begin{array}{l}3 \\
4 \\
2 \\
3 \\
0 \\
1\end{array}$ & $\begin{array}{r}3 \\
11 \\
12 \\
10 \\
14 \\
9\end{array}$ & $\begin{array}{l}8 \\
6 \\
5 \\
5 \\
5 \\
2\end{array}$ & $\begin{array}{l}3 \\
2 \\
2 \\
2 \\
1 \\
3\end{array}$ & $\begin{array}{l}5 \\
1 \\
2 \\
3 \\
3 \\
9\end{array}$ \\
\hline
\end{tabular}

Note $-\bar{p}=$ not $p ; \bar{q}=$ not $q$.

next most frequent response ("not q"), not entered separately in the table, only occurred 16 times out of the possible 432 responses.

For these data and those in the subsequent experiments, chi-square statistical tests and a $p=.05$ level of significance were employed.

By far the most frequent response to the DAP was the correct $p$ and not-q combination (87/144). This replicates the previous finding of Griggs and Cox (in press). However, this response occurred significantly less often when the problem did not appear first. The selection occurred $36 / 48$ times in the first position, in contrast with $25 / 48$ times in the second position and $26 / 48$ in the third position. Thus, the other two problems apparently interfered with the DAP when they preceded it. Both problems seemed to have the same effect. Because this was an unexpected effect and because it was observed in all three experiments, it will be discussed later, in the General Discussion section.

The most frequent response to the ACP problem was also the logically correct $p$ and not-q selection. When the ACP was presented first, the correct solution was obtained significantly more often than for the AP presented first $(12 / 48$ vs. $2 / 48)$. This result supports the memory-cuing/reasoning-by-analogy hypothesis, as do the following findings. When the ACP appeared second, 18 of 24 subjects made the correct selection when the ACP followed the DAP, and only 4 of 24 subjects made this selection when the ACP followed the AP. This difference was highly significant $(p<.0001)$. Further- more, the performance on the ACP following the DAP was significantly higher than when the ACP was presented first $(18 / 24$ vs. $5 / 24$ or $7 / 24)$. When the ACP was presented third, the correct response rate was $28 / 48$, significantly greater than when the ACP was presented first, but not significantly different from performance obtained on the problem when it was in the second position following the DAP.

In further support of the hypothesis, the AP, when presented first, yielded a correct response rate of only $2 / 48$. This level of performance did not change significantly regardless of the AP's presentation position. In fact, no selection frequency for this problem differed significantly as a function of presentation position, except for an anomalous difference in the frequency of the $p$ and $q$ selection for the two groups receiving the AP first. In agreement with past studies, the most frequent response (59/144) to the AP was $p$ and $q$. The next most frequent response (31/144) was the not-p and not-q response. Yachanin and Tweney (1982) also found this to be a frequent selection for the abstract task. Both of these responses ( $p$ and $q$ and not $p$ and not q) occurred significantly less often for the DAP and ACP.

\section{EXPERIMENT 2}

The results of Experiment 1, as well as those of D'Andrade (see Rumelhart, 1980, Note 2), Golding (Note 1), Griggs and Cox (in press), and Mandler (Note 3) indicate that the relationship between the subjects' past experience and the specific statement of the selection task is extremely important to successful performance in the selection task. Thus, the familiarity of the implication rule provides an interesting test of the memory-cuing hypothesis. Because the contrapositive (If not $\mathrm{q}$, then not $\mathrm{p}$ ) of an implication relationship has the same counterexample as the implication rule itself and leaves the logical relationship between the selection values unchanged, it is possible to vary the familiarity of the rule statement without changing the logical properties of the problem. The memory-cuing hypothesis would predict better performance for the more familiar statement of the relationship. The contrapositive statement of the DAP rule is, "If a person is under 19, then the person must be drinking Coke." This rule would be less familiar to college undergraduates than the DAP rule, and thus the probability of the appropriate information in memory being cued is less. However, as in the DAP, the violator to this rule is the person under 19 who is drinking beer.

Experiment 2 examined performance on the DAP and its contrapositive and possible transfer between the two problems.

\section{Method}

Subjects. Forty eight undergraduates at the University of Florida participated as part of course requirements for an 
Table 2

Selection Frequencies for the DAP and the C-DAP as a Function of Presentation Position in Experiment 2

\begin{tabular}{lcccc} 
& \multicolumn{4}{c}{ Selection } \\
\cline { 2 - 5 } Problem & $\mathrm{p}, \overline{\mathrm{q}}$ & $\mathrm{p}$ & $\overline{\mathrm{q}}$ & Other \\
\hline & \multicolumn{4}{c}{ Order: DAP, C-DAP } \\
DAP & 22 & 0 & 1 & 1 \\
C-DAP & 12 & 3 & 3 & 6 \\
& & Order: C-DAP, DAP & \\
DAP & 14 & 4 & 2 & 4 \\
C-DAP & 13 & 2 & 2 & 7 \\
\hline
\end{tabular}

Note-DAP $=$ drinking-age problem, $C-D A P=$ contrapositive drinking-age problem; $\bar{p}=$ not $p, \bar{q}=$ not $q$.

introductory class in psychology. None had participated in Experiment 1.

Design. Twenty-four subjects were randomly assigned to a group receiving the DAP problem followed by the same problem but with the contrapositive of the implication rule. The other half of the subjects received the problems in reverse order. Subjects were run in groups ranging in size from 10 to 24 .

Materials and Procedure. The procedure of Experiment 2 was identical to that of Experiment 1 . The two problems that were presented were the DAP and the contrapositive of the DAP (C-DAP). The rule used in the C-DAP was, "If a person is under 19, then the person must be drinking Coke." The format of the problems was like that used in Experiment 1.

\section{Results and Discussion}

Table 2 presents the selection frequencies greater than two for each of the problems as a function of presentation position. When presented first, the proportion correct was significantly higher for the DAP than for the C-DAP $(22 / 24$ vs. 13/24). However, due to a significant decrease in the proportion correct for the DAP when it followed the C-DAP (from 22/24 to 14/24), there was no significant difference in the correct response rates between the problems when presented second.

These data confirm the prediction of better performance on the rule statement that is more familiar to the subjects. They also provide further evidence of negative transfer in the selection task. As in Experiment 1, proportion correct for the DAP was significantly reduced when it was preceded by a problem that does not lend itself as readily to memory cuing.

\section{EXPERIMENT 3}

Experiment 2 varied the familiarity of the implication rule by employing a familiar rule's contrapositive. This had the advantage of keeping the logical relation among the values presented on the selection cards and the pertinent counterexample constant while manipulating the familiarity of the rule. Another approach would be to use a familiar rule's converse (If $\mathrm{q}$, then $\mathrm{p}$ ). In this case, the terms named in the new rule would be the same as in the familiar rule, but the relationship expressed and the rule's counterexample are directly contrary to the subjects' experience.

The rule "If a person is over 19, then the person must be drinking beer" uses the same terms as the DAP rule. However, the violator to this rule is a person over 19 and drinking Coke. The counterexample, then, is the exact opposite of the one recalled when the familiar relationship is considered. Experiment 3 investigated the effect of changing the relationship stated in the DAP rule so that it is directly against the subjects' past experience. Facilitation for the converse rule would provide strong evidence for the memory-cuing/reasoningby-analogy hypothesis. The effect of order of presentation was also considered.

\section{Method}

Subjects. Forty-ight undergraduates at the University of Florida participated as part of course requirements for an introductory class in psychology. None had participated in Experiments 1 and 2.

Design. Two groups in which the order of presentation of two problems was varied were formed. Twenty-four subjects were randomly assigned to each group by the order they signed up for participation.

Materials and Procedure. The procedures in Experiment 3 were the same as those in Experiments 1 and 2. The materials consisted of two problems. One problem was the DAP; the other problem was exactly like the DAP except the rule given was, "If a person is over 19, then the person must be drinking beer." This problem is referred to as the against-experience DAP (AE-DAP).

\section{Results and Discussion}

Table 3 presents the selection frequencies greater than two for each of the problems as a function of presentation position. As in Experiments 1 and 2, subjects performed better on the DAP, which employs the familiar rule. The correct response rate for the DAP presented first $(23 / 24)$ was significantly higher than for the AE.DAP presented first $(5 / 24)$ or second $(12 / 24)$. However, as in the first two experiments, performance on the DAP was subject to interference by a preceding problem. Proportion correct for the DAP dropped significantly when it followed the AE-DAP (from 23/24 to $15 / 24)$.

Table 3

Selection Frequencies for the DAP and AE-DAP as a Function of Presentation Position in Experiment 3

\begin{tabular}{lrrrrrr}
\hline & \multicolumn{6}{c}{ Selection } \\
\cline { 2 - 6 } Problem & $\mathrm{p}, \overline{\mathrm{q}}$ & $\mathrm{p}$ & $\mathrm{p}, \mathrm{q}$ & $\overline{\mathrm{p}}, \mathrm{q}$ & $\overline{\mathrm{p}}, \overline{\mathrm{q}}$ & Other \\
\hline \multicolumn{6}{c}{ Order: DAP, AE-DAP } \\
DAP & 23 & 0 & 0 & 0 & 0 & 1 \\
AE-DAP & 12 & 1 & 2 & 6 & 0 & 3 \\
& 15 & 3 & 1 & 0 & 2 & 3 \\
DAP & 5 & 0 & 4 & 5 & 3 & 7 \\
AE-DAP & \multicolumn{7}{c}{ Order: AE-DAP, DAP } \\
\hline
\end{tabular}

Note-DAP $=$ drinking-age problem, $A E-D A P=$ against-experience drinking-age problem; $\bar{p}=$ not $p ; \bar{q}=$ not $q$. 
Consistent with the memory-cuing/reasoning-byanalogy hypothesis, performance on the AE-DAP was significantly better when it followed the DAP (12/24 vs. 5/24). The $q$ and not-p selection occurred significantly more often for the AE-DAP when presented first or second compared to the DAP (6/24 vs. 0/24 and $5 / 24$ vs. $0 / 24$, respectively). Such a high proportion of $\mathrm{q}$ and not-p selections has not been reported previously. However, this finding can be explained by the memory-cuing hypothesis. The $q$ and not-p response to the AE-DAP is the selection of the person drinking beer and the person under 19 years of age as the possible violators of the rule. Thus, this selection constitutes the counterexample to the familiar DAP rule. Subjects making this selection could be terminating cognitive processing for the problem with the recall of the familiar relationship and its counterexample. That is, they do not go on and complete the analogical reasoning process to obtain the correct answer.

\section{GENERAL DISCUSSION}

The present experiments provide ample evidence that subjects' extraexperimental experience has a significant impact on performance on the Wason selection task. The pattern of results obtained for the five versions examined is consistent with the memory-cuing/reasoningby-analogy hypothesis in that the proportion of correct selections was related to the degree to which each version was analogous to the subjects' past experience.

The DAP, C-DAP, and AE-DAP have the same general thematic presentation and the same terms as selection choices. However, they differ systematically in their similarity to the subjects' extraexperimental experience. The DAP is most similar: The rule statement and, thus, the logical relation among the selection choices are in agreement with the subjects' experience. The correct selection rate for this problem when presented first in the three present experiments was $81 / 96(84 \%)$.

The logical relations among the selection choices for the C-DAP are identical to those for the DAP; however, the rule statement is unfamiliar to the subjects. Therefore, this problem is intermediate in its similarity to the subjects' prior experience, and an intermediate correct selection rate was obtained $(13 / 24$ or $54 \%)$. The AE-DAP is less analogous to the subjects' prior experience; both the logical relations among the selection choices and the rule statement are unfamiliar. The correct selection rate for this problem when presented first was $5 / 24(21 \%)$.

The correct selection rate for the ACP when presented first (12/48 or 25\%) was comparable to that for the AE-DAP. In addition, this rate increased to $50 \%$ for both of these problems when they followed the DAP, a positive effect of intraexperimental experience. The lowest correct selection rate was obtained for the AP: $2 / 48(4 \%)$ when presented first and only $5 / 144$ $(3 \%)$ overall.
Although all the findings discussed above are consistent with the memory-cuing/reasoning-by-analogy hypothesis, an unexpected result was found: The correct selection rate on the DAP significantly decreased when it was preceded by any of the other problems. This was observed in all three experiments. In most previous studies, problem content has been counterbalanced, and negative transfer effects have not been reported. There was no pattern to the selections made by the subjects who responded incorrectly to the DAP when it followed another problem. In each experiment, these subjects made from five to seven different selections. The percentage of subjects who missed the DAP and selected the same cards that they chose on the preceding problem was also computed for each experiment. Such repetitive responding accounted for less than $50 \%$ of the incorrect selections on the DAP when not presented first (36\% in Experiment 1 and 44\% in both Experiments 2 and 3). Because of this and because of the variability in the erroneous selections, the negative transfer result is not readily explainable and provides a problem for further investigation.

In conclusion, it appears that a subject's performance on Wason's selection task is primarily determined by the relationship of the task content and the subject's prior experience with that content as detailed in the memorycuing hypothesis. Additionally, when given more than one version of the task, intraexperimental experience may also affect a subject's selection. Depending upon the relationship between the versions and their order of presentation, the correct selection may be facilitated or hampered.

\section{REFERENCE NOTES}

1. Golding, E. The effect of past experience on problem solving. Paper presented at the Annual Conference of the British Psychological Society, Surrey University, April 1981.

2. Rumelhart, D. E. Analogical processes and procedural representations (Tech. Rep. 81). La Jolla, Calif: University of California, San Diego, Center for Human Information Processing, 1979.

3. Mandler, J. M. Structural invariants in development (Tech. Rep. 96). La Jolla, Calif: University of California, San Diego, Center for Human Information Processing, 1980.

\section{REFERENCES}

Bracewell, R. J., \& Hidi, S. W. The solution of an inferential problem as a function of stimulus materials. Quarterly Journal of Experimental Psychology, 1974, 26, 480-488.

Brown, C., Keats, J. A., Keats, D. M., \& Segore, I. Reasoning about implication: A comparison of Malaysian and Australian subjects. Journal of Cross-Cultural Psychology, 1980, 11, 395 410.

Evans, J. St.B. T. The psychology of deductive reasoning. London: Routledge \& Kegan Paul, 1982.

Evans, J. St.B. T. Selective processes in reasoning. In J. St.B. T. Evans (Ed.), Thinking and reasoning: Psychological approaches. London: Routledge \& Kegan Paul, in press.

Griggs, R. A. The role of problem content in the selection task and THOG problem. In J. St.B. T. Evans (Ed.), Thinking and reasoning: Psychological approaches. London: Routledge \& Kegan Paul, in press. 
Griggs, R. A., \& Cox, J. R. The elusive thematic-materials effect in Wason's selection task. British Journal of Psychology, in press.

Johnson-Laird, P. N., Legrenzi, P., \& Sonino-Legrenzi, M. Reasoning and a sense of reality. British Journal of Psychology, $1972,63,395-400$.

Manktelow, K. I., \& Evans, J. St.B. T. Facilitation of reasoning by realism: Effect or non-effect? British Journal of Psychology, 1979, 70, 477-488.

Pollard, P. The effect of thematic content on the 'Wason selection task.' Current Psychological Research, 1981, 1, 21-29.

REICH, S. S., \& RUTH, P. Reasoning: Verification, falsification and matching. British Journal of Psychology, in press.

Rumelhart, D. W. Schemata: The building blocks of cognition. In R. J. Spiro, B. C. Bruce, \& W. F. Brewer (Eds.), Theoretical issues in reading comprehension. Hillsdale, N.J: Erlbaum, 1980.

VAN DuYNe, P. C. Realism and linguistic complexity in reasoning. British Journal of Psychology, 1974, 65, 59-67.

Wason, P. C. Reasoning. In B. Foss (Ed.), New horizons in psychology. London: Penguin, 1966.

WAson, P. C. Reasoning about a rule. Quarterly Journal of Experimental Psychology, 1968, 20, 273-281.
Wason, P. C., \& Johnson-Laird, P. N. Psychology of reasoning: Structure and content. Cambridge, Mass: Harvard University Press, 1972.

Wason, P. C., \& Shapiro, D. Natural and contrived experience in a reasoning problem. Quarterly Journal of Experimental Psychology, 1971, 23, 63-71.

Yachanin, S. A., \& Tweney, R. D. The effect of thematic content on cognitive strategies in the four-card selection task. Bulletin of the Psychonomic Society, 1982, 19, 89-90.

\section{NOTE}

1. Bracewell and Hidi (1974) also observed good performance (75\% correct selections) for their concrete/natural relationship problems. However, a procedural difference in this study confounds the interpretation of the data (see Griggs \& Cox, in press).

(Received for publication October 16, 1981; revision accepted June 3, 1982.) 